\title{
MÉTODO SIMPLES PARA ESTIMAR ENCURTAMENTO PELO FRIO EM CARNE BOVINA
}

\author{
A SIMPLE METHOD TO ESTIMATE COLD SHORTENING IN BEEF
}

\author{
Riana Jordão Barrozo Heinemann ${ }^{1}$ Marcos Franke Pinto ${ }^{2}$ \\ Elisa Helena Giglio Ponsano ${ }^{3}$ Silvia Helena Venturoli Perri ${ }^{4}$
}

RESUMO

É bem conhecido o fato de que o encurtamento pelo frio pode influenciar negativamente a textura da carne. Por isso, a determinação do grau de contração do tecido muscular é um recurso analítico de grande importância quando se estuda a otimização dos procedimentos industriais. Neste trabalho, foram avaliadas comparativamente duas metodologias de microscopia. Para isso, os músculos Biceps femoris, Longissimus dorsi e Semimembranosus obtidos de nove carcaças bovinas com três diferentes graus de acabamento foram analisados de forma pareada por ambos os métodos. O músculo Longissimus dorsi apresentou menor comprimento de sarcômero $e$ o $\mathrm{m}$. Semimembranosus o maior $(p<0,05)$. As amostras com maior espessura de gordura de cobertura apresentaram maior comprimento de sarcômero $(p<0,05)$. Não houve diferença significativa entre os valores obtidos pelas duas metodologias estudadas ( $p>0,05)$, revelando a possibilidade de emprego do método mais simples.

Palavras-chave: carne, maciez, sarcômero, encurtamento pelo frio

SUMMARY

The negative influence of cold shortening on meat texture is well known. Because of that, the determination of the muscle contraction extent represents an important analytical tool for the optimization of the industrial procedures. In this work, two methodologies to evaluate cold shortening were compared. Biceps femoris, Longissimus dorsi and Semimembranosus muscles from 9 cattle carcasses with three different fat thickness grades were paired analyzed by both methodologies.
Longissimus dorsi muscle showed the shortest sarcomere length while Semimembranosus $m$. showed the longest one $(p<0.05)$. Samples with higher fat thickness showed longer sarcomere length ( $p<0.05)$. There was no significant difference between the two methodologies studied ( $p>0.05)$, which suggests the possibility of using the simpler method for cold shortening evaluation.

Key words: beef, tenderness, sarcomere, cold shortening.

\section{INTRODUÇÃO}

Há muito tempo é conhecido o fato de que músculos vermelhos tendem a se contrair quando expostos ao frio em estágios anteriores ao estabelecimento do rigor mortis (PARRISH et al., 1973; CULLER et al., 1978; LOCHNER et al., 1980; JUDGE et al., 1989; OLSSON et al., 1994). Esse fenômeno, conhecido como encurtamento pelo frio (cold shortening), pode causar um aumento de quatro a cinco vezes na força necessária para cisalhar um pedaço de carne (MARSH, 1977). A eficiência das câmaras de resfriamento sempre mereceu atenção dos frigoríficos, pela necessidade de acelerar o processamento e inibir o crescimento microbiano. Assim, o encurtamento pelo frio passou a ter papel predominante na textura da carne. Diante

\footnotetext{
${ }^{1}$ Engenheira de Alimentos, Bolsista da Fapesp de Capacitação Técnica. Departamento de Apoio, Produção e Saúde Animal, Medicina Veterinária, Universidade Estadual Paulista (UNESP), Araçatuba -SP.

${ }^{2}$ Médico Veterinário, Professor Assistente Doutor do Departamento Apoio, Produção e Saúde Animal, Medicina Veterinária, UNESP, 16050-680, Araçatuba, SP. CP 341. E-mail: mfpinto@fmva.unesp.br . Autor para correspondência.

${ }^{3}$ Farmacêutico-Bioquímico, Professor Assistente Doutor do Departamento Apoio, Produção e Saúde Animal, Medicina Veterinária, UNESP / Araçatuba - SP.

${ }^{4}$ Estatístico, Professor Assistente Doutor do Departamento Apoio, Produção e Saúde Animal. Medicina Veterinária - Unesp/Araçatuba SP.
} 
disso, a aferição do grau de encurtamento do tecido muscular pode ser de grande importância para a otimização do manejo tecnológico do produto.

Para análise de comprimento do sarcômero, foram desenvolvidas diversas técnicas. Segundo CROSS et al. (1981), os métodos mais acessíveis e mais usados baseiam-se em análise micrométrica, nas quais são medidos os espaços entre linhas $\mathrm{Z}$ adjacentes. Outros princípios de medição de comprimento de sarcômero são utilizados, como a técnica por refração a laser utilizada por CROSS et al. (1981), KOOHMARAIE et al. (1996) e PURCHAS et al. (1999).

Neste trabalho, foi avaliado um método analítico simplificado, baseado em análise micrométrica, para estimar o grau de encurtamento do tecido muscular. Os resultados obtidos por esse método foram comparados aos obtidos com metodologia já descrita na literatura científica, citada por MOLLER et al. (1973), OLSON \& PARRISH (1977) e CULLER et al. (1978). Essas metodologias apresentam o mesmo princípio de medição de distância entre as zonas $\mathrm{Z}$ do sarcômero, porém diferem na facilidade de preparação da amostra. $\mathrm{O}$ objetivo foi tornar disponível uma metodologia analítica mais rápida, simples e acessível para estimar o grau de contração do tecido muscular.

\section{MATERIAL E MÉTODOS}

As amostras foram obtidas de nove carcaças de novilhos Nelore jovens (com até quatro dentes da segunda dentição) e de conformação retilínea, segundo o Sistema Nacional de Tipificação de Carcaças Bovinas (BRASIL, 1989). Os animais foram abatidos de acordo com as normas do RIISPOA (BRASIL, 1997) no Frigorífico Bertin Ltda., localizado no município de Lins - SP. Essas carcaças foram divididas em três grupos com base no acabamento. O primeiro grupo constituiu-se de três carcaças com gordura de cobertura escassa (grau de acabamento 2). O segundo grupo consistiu de três carcaças com gordura de cobertura mediana (grau 3), e o terceiro grupo em três carcaças com gordura de cobertura uniforme (grau 4). Após o abate, as carcaças foram mantidas em câmara fria a $2^{\circ} \mathrm{C}$ por 24 horas, sendo em seguida encaminhadas para a seção de desossa, onde foram selecionados os músculos Biceps femoris, Longissimus dorsi e Semimembranosus. As amostras tomadas desses músculos foram divididas em duas frações e congeladas, sendo posteriormente analisadas por ambos os métodos pareadamente.

$\mathrm{O}$ primeiro método foi baseado no procedimento descrito por OLSON \& PARRISH
(1977), que neste trabalho será denominado "método controle". Com base nessa metodologia, as amostras congeladas foram finamente desbastadas com auxílio de um estilete. Após a retirada de toda gordura aparente, $4 \mathrm{~g}$ de amostra foram colocados em sacos de polietileno e adicionados de uma solução denominada no trabalho original de "solução de isolamento", constituída de $\mathrm{KCl} 100 \mathrm{mM}, \mathrm{KPO}_{4}$ $20 \mathrm{mM}$, EDTA $1 \mathrm{mM}$ e azida sódica $1 \mathrm{mM}$, na razão de 10:1 (v/p) para homogeneização em aparelho tipo Stomacher por 3 minutos. A suspensão obtida foi homogeneizada por 30 segundos em liquidificador industrial e, em seguida, centrifugada por $1000 \times \mathrm{x}$ por $15 \mathrm{~min}$. $\mathrm{O}$ sedimento foi recolhido $\mathrm{e}$ homogeneizado com 10vol. (v/p) da mesma solução para, em seguida, ser centrifugado novamente por 1000 x $g$ por 15 minutos. Descartado o sobrenadante, o sedimento foi então homogeneizado com mais 10vol. (v/p) da solução de isolamento e passado por peneira metálica (18 mesh) para remoção de tecido conectivo. A suspensão obtida foi diluída na razão de 1:5 (p/v) na mesma solução, e uma alíquota de cerca de $0,1 \mathrm{~m} \ell$ foi transferida para lâmina, sobreposta por lamínula e imediatamente analisada em microscópio ótico em aumento de 1000x.

No método proposto, denominado neste trabalho de "método experimental", as amostras congeladas foram finamente desbastadas com estilete, e $4 \mathrm{~g}$ foram colocados em sacos de polietileno. Foram adicionados 10vol. (v/p) de solução de $\mathrm{KCl}$ 0,6M para homogeneização em aparelho Stomacher por 3 minutos. A solubilidade das proteínas miofibrilares nessa solução foi previamente determinada por BISCONTINI et al. (1996) e SHIMOKOMAKI et al. (1998). Essa suspensão foi, então, passada por peneira metálica (18 mesh), e uma alíquota de cerca de $0,1 \mathrm{~m} \ell$ foi transferida para lâmina, sobreposta por lamínula, e imediatamente analisada em microscópio ótico em aumento de 400x.

Foi utilizado o Sistema Analisador de Imagens LEICA Q550IW para determinar o comprimento dos sarcômeros das amostras. Em ambos os métodos, em cada medição, foi utilizado o maior número possível de sarcômeros, tendo como base as bandas A e I, uma vez que a visualização da linha $\mathrm{Z}$ não foi possível. A distância verificada foi dividida pelo número de sarcômeros, a fim de minimizar os erros de medição. Foram realizadas pelo menos 10 medições em campos diferentes para cada amostra.

Os dados obtidos foram analisados utilizando-se o procedimento GLM - General Linear Models - no programa SAS - Statistical Analysis 
System (1996). O método analítico empregado, o músculo utilizado e o grau de cobertura de gordura foram considerados como variáveis independentes na análise de variância e teste Duncan.

\section{RESULTADOS E DISCUSSÃO}

Nas figuras 1 e 2, são apresentadas imagens obtidas com os diferentes métodos. É possível observar que, com o método experimental, são obtidos feixes maiores de miofibrilas, enquanto com o método controle a fragmentação é maior, originando miofibrilas soltas. Essa diferença foi o principal motivo da realização deste trabalho. Considerando que o método experimental requer uma preparação muito mais simples e rápida, avaliou-se a possibilidade de comparação dos resultados obtidos pelos dois métodos.

A análise de variância revelou não haver interação significativa $(p>0,05)$ entre as variáveis estudadas. Na tabela 1, são apresentadas as médias dos valores obtidos de todas as amostras analisadas para cada um dos métodos. É possível constatar que os valores de comprimento do sarcômero não diferem significativamente $(\mathrm{p}>0,05)$ quando medidos pelos diferentes métodos estudados. Além disso, os resultados observados encontram-se dentro da faixa de variação de valores reportados em outros trabalhos realizados em condições semelhantes (BOUTON et al., 1978; PARRISH et al., 1973; UYTTERHAEGEN et al., 1994). Assim, foi possível demonstrar a validade do emprego da metodologia mais simples. Além da maior facilidade e menor tempo requerido no preparo da amostra, o
Tabela 1 - Comprimento de sarcômero das amostras analisadas pelos dois diferentes métodos.

\begin{tabular}{lccc}
\hline Método de análise & $\mathrm{n}$ & Média $(\square \mathbf{m})$ & Desvio padrão \\
\hline Método controle & 27 & $1,886^{\mathrm{a}}$ & 0,169 \\
Método experimental & 27 & $1,882^{\mathrm{a}}$ & 0,155
\end{tabular}

${ }^{a}$ Médias seguidas de mesma letra não diferem significativamente $(\mathrm{P}>0,05)$

método proposto facilita a aferição micrométrica, uma vez que as miofibrilas dispostas em feixes apresentam-se menos curvas do que as estruturas soltas observadas com o emprego do método controle.

Na tabela 2, são apresentadas as médias dos valores observados em todas as amostras de cada músculo com ambos os métodos e com os diferentes níveis de cobertura de gordura. Observouse que o m. Longissimus dorsi apresentou menor comprimento de sarcômero e o m. Semimembranosus o maior $(\mathrm{p}<0,05)$. BOUTON et al. (1978), trabalhando com esses mesmos músculos provenientes de animais de diferentes idades, encontraram valores de comprimento de sarcômero sempre maiores para o m. Semimembranosus. OLSSON et al. (1994) também trabalharam com os músculos L. dorsi e Semimembranosus mantidos em diferentes temperaturas após o abate (entre 1 e $10^{\circ} \mathrm{C}$ ) e observaram que o grau de encurtamento do m. L. dorsi foi sempre maior. NORMAN (1982), por sua vez, observou uma variação considerável no comprimento do sarcômero entre músculos de uma

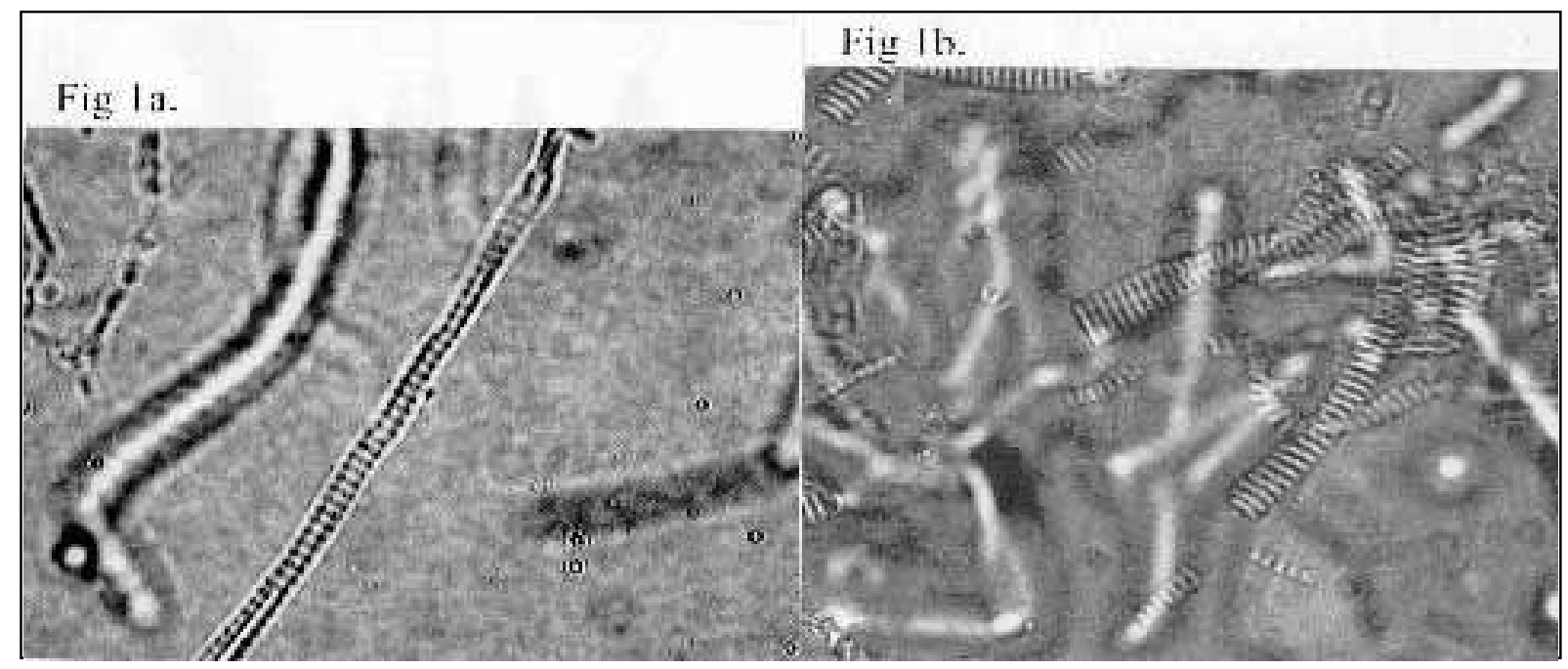

Figura 1 - Miofibrilas soltas obtidas pelo método controle, em que se observam as estriações correspondentes às bandas A e I, empregadas na aferição micrométrica. Microscópio ótico, aumento 1000x. (m. Longissimus dorsi).

Ciência Rural, v. 32, n. 2, 2002. 


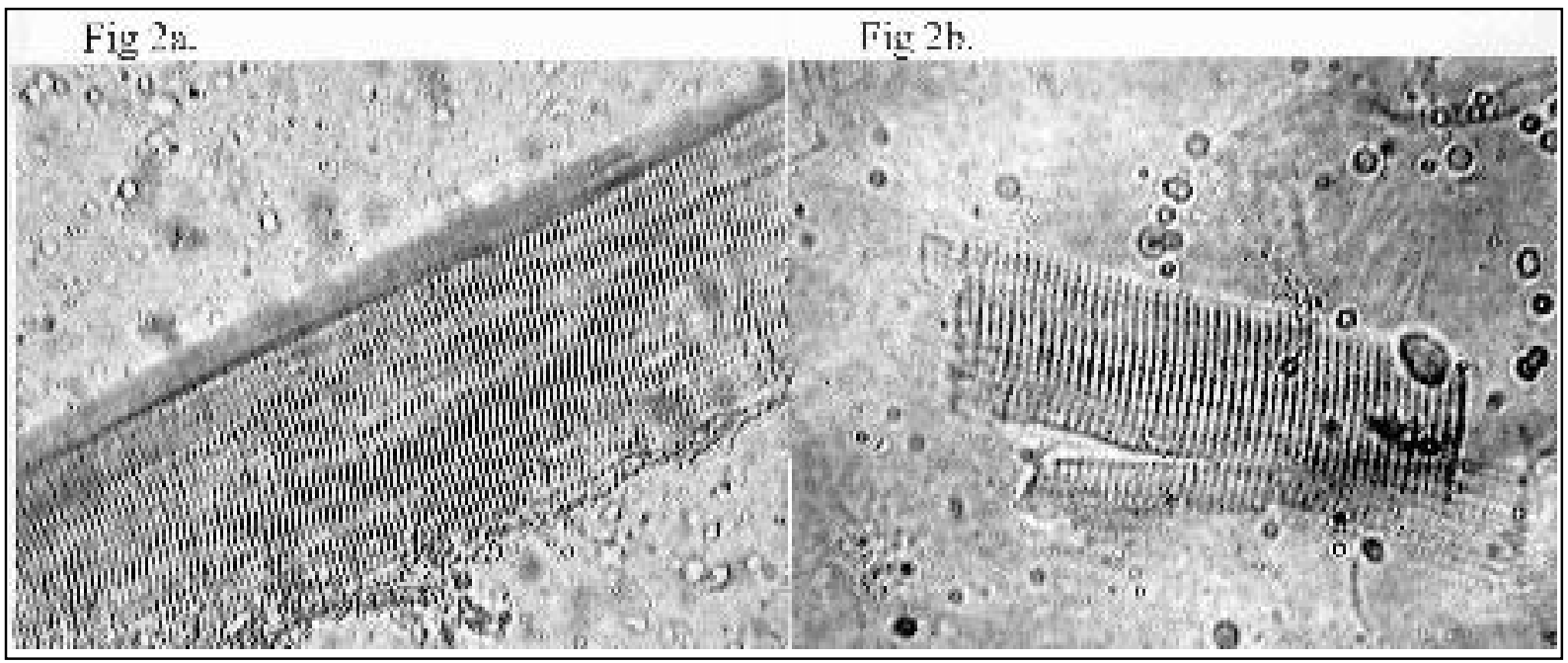

Figura 2 - Feixes de miofibrilas obtidos pelo método analítico 2. Microscópio ótico, aumento 400x.( m. Longissimus dorsi).

Tabela 2 - Comprimento de sarcômero das amostras tomadas de diferentes músculos.

\begin{tabular}{|c|c|c|c|}
\hline Músculo & $\mathrm{n}$ & Média $(\square \mathbf{m})$ & Desvio padrão \\
\hline Biceps femoris & 18 & $1,88^{a, b}$ & 0,15 \\
\hline Longissimus dorsi & 18 & $1,82^{\mathrm{a}}$ & 0,16 \\
\hline Semimembranosus & 18 & $1,95^{\mathrm{b}}$ & 0,15 \\
\hline
\end{tabular}

mesma carcaça. Isso pode ser explicado pela forma e localização anatômica dos cortes, uma vez que a velocidade de resfriamento será maior em músculos com menor secção transversal e localizados em posições mais expostas.

BOUTON et al. (1978) concluíram que ocorrerá diferença no comprimento do sarcômero de amostras provenientes de diferentes grupos de animais se as condições de resfriamento induzirem à ocorrência do encurtamento e se as diferenças de idade, teor de gordura e peso forem suficientes para promover diferentes velocidades de resfriamento dos músculos.

Na tabela 3, são apresentadas as médias dos valores correspondentes às amostras de carcaças com diferentes graus de acabamento obtidos com ambos os métodos. Os resultados indicam que amostras provenientes de carcaças com maior cobertura de gordura (grau de acabamento 4) apresentaram maior comprimento de sarcômero, enquanto que as amostras tomadas de carcaças com menor cobertura de gordura (grau 2) apresentaram menor comprimento de sarcômero. Isso é provavelmente resultado do efeito protetor da gordura, retardando o resfriamento do tecido e prevenindo o fenômeno do encurtamento pelo frio.
Tabela 3 - Comprimento do sarcômero das amostras tomadas de carcaças com diferentes graus de cobertura de gordura.

\begin{tabular}{|c|c|c|c|}
\hline Gordura de cobertura & $\mathrm{n}$ & Média $(\square \mathrm{m})$ & Desvio padrão \\
\hline Escassa - grau 2 & 18 & $1,83^{\mathrm{a}}$ & 0,14 \\
\hline Mediana - grau 3 & 18 & $1,87^{\mathrm{a}, \mathrm{b}}$ & 0,15 \\
\hline Uniforme - grau 4 & 18 & 1,95 b & 0,18 \\
\hline
\end{tabular}

BOUTON et al. (1978) citam que o comprimento do sarcômero aumenta com o aumento do teor de gordura em carcaças de bovinos com mesma idade e pesos diferentes. Os autores verificaram que, em carcaças mais leves (menos que $250 \mathrm{~kg}$ ), as condições de resfriamento foram suficientes para provocar encurtamento pelo frio, uma vez que a temperatura central da carcaça atinge temperaturas menores mais rapidamente, o que não ocorre em carcaças mais pesadas. Segundo MARSH (1977), o encurtamento é prevenido se o rigor mortis se iniciar antes do tecido atingir uma temperatura abaixo de $10^{\circ} \mathrm{C}$. HERTZMAN et al. (1993) afirmam que o encurtamento é mínimo quando a temperatura no início do rigor situa-se entre 15 e $20^{\circ} \mathrm{C}$ (aproximadamente $10 \%$ do comprimento muscular). Abaixo dessa faixa, ocorre um encurtamento maior, que pode chegar a $50 \%$. Se a sobreposição dos miofilamentos resulta num encurtamento superior a $20 \%$, ocorre prejuízo perceptível da maciez. Esse efeito de endurecimento aumenta até um pico em torno de $40 \%$ de encurtamento.

$\mathrm{O}$ encurtamento pelo frio não é o único fator que influencia a maciez da carne, mas assume maior importância quando a carne é exposta a condições que propiciam sua ocorrência, o que se 
verifica freqüentemente em frigoríficos brasileiros. No entanto, retardar o resfriamento das carcaças é inviável, por favorecer o desenvolvimento microbiano e ferir as normas legais (BRASIL, 1997). Além disso, implicaria aumento de tempo e de espaço necessários à refrigeração. Isso justifica a importância de viabilizar metodologias acessíveis que permitam aferir o comprimento do sarcômero, constituindo-se num importante auxílio para a orientação dos diversos setores envolvidos na cadeia de produção de carne na busca por soluções que resultem na otimização da qualidade do produto.

\section{CONCLUSÕES}

Com este trabalho, foi possível disponibilizar uma metodologia simples e rápida de determinação do grau de contração do tecido muscular, que poderá ser utilizada como uma importante ferramenta na otimização dos procedimentos tecnológicos pós-abate, a fim de prevenir ou reduzir a ocorrência do fenômeno de encurtamento pelo frio.

\section{AGRADECIMENTO}

Os autores agradecem à FAPESP pelo auxílio financeiro

\section{REFERÊNCIAS BIBLIOGRÁFICAS}

BISCONTINI, T.M.B., SHIMOKOMAKI, M., OLIVEIRA, S.O. et al. An ultrastructural observation on charquis, salted and intermediate moisture meat products. Meat Science, Oxford, v.43, n.3-4, p.351-358, 1996

BOUTON, P.E., FORD, A. L., HARRIS, P. V., et al. Influence of animal age on the tenderness of beef: muscle differences. Meat Science, Oxford, v.2, p.301-311, 1978.

BRASIL. Ministério da Agricultura. Decreto lei $n^{0} 2.244,5$ jun., 1997. Regulamento da inspeção industrial e sanitária de produtos de origem animal. Brasília, 1997. 204p.

BRASIL. Ministério da Agricultura. Portaria n ${ }^{\circ} 612,5$ out. 1989. Sistema nacional de tipificação de carcaças bovinas Brasília, 1989. 5p.

CROSS, H.R., WEST, R.L., DUTSON, T.R. Comparison of methods for mesuring sarcomere length in beef semitendinosus muscle. Meat Science, Oxford, v.5, n.4, p.261-266, 1981.

CULLER, R.D., PARRISH JR., F.C., SMITH, G.C., et al. Relationship of miofibril fragmentation index to certain chemical, phisical and sensory characteristic of bovine longissimus muscle. Journal of Food Science, Chicago, v.43, p.1177-1180, 1978.

HERTZMAN, C., OLSSON, U., TORNBERG, E. The influence of high temperature, type of muscle and electrical stimulation on the course of rigor, ageing and tenderness of beef muscles. Meat Science, Oxford, v.35, p.119-141, 1993.

JUDGE, M.D., ABERLE, E.D., FORREST, J.C. et al. Principles of meat science. 2ed. Iowa : Kendall Hunt, 1989. 351p.

KOOHMARAIE, M., DOUMIT, M.E., WHEELER, T.L. Meat toughening does not occur when rigor shortening is prevented. Journal of Animal Science, Champaign, v.74, n.12, p.2935-2942, 1996.

LOCHNER, J.V., KAUFFMAN, R.G., MARSH, B.B. Early postmortem cooling rate and beef tenderness. Meat Science, Oxford, v. 4, p. 227-241, 1980.

MARSH, B.B. Basis of tenderness in muscle foods. Journal of Food Science, Chicago, v.42, n.2, p.295-297, 1977.

MOLLER, A. J., VESTERGAARD, T., WISMER-PEDERSEN, J Miofibril fragmentation in bovine longissimus dorsi as an index of tenderness. Journal of Food Science, Chicago, v.38, n.5, p.824-825, 1973.

NORMAN, G.A. Effect of breed and nutrition on the productive traits of beef cattle in south-east Brazil: Part 3 - meat quality. Meat Science, Oxford, v.6, n.2, p.79-96, 1982.

OLSSON, U., HERTZMAN, C., TORNBERG, E. The influence of low temperature, type of muscle and electrical estimulation on the course of rigor mortis, ageing and tenderness of beef muscles. Meat Science, Oxford, v.37, p.115-131, 1994.

OLSSON, D.G., PARRISH JR., F.C. Relationship of miofibril fragmentation index to measures of beefsteak tenderness. Journal of Food Science, Chicago, v.42, n.2, p.506-509, 1977.

PARRISH, F.C., YOUNG, R.B., MINER, B.E. et al. Effect of postmortem conditions on certain chemical, morphological and organoleptic properties of bovine muscle. Journal of Food Science, Chicago, v.38, p.690-695, 1973.

PURCHAS, R.W., YAN, X., HARTLEY, D.G. The influence of a period of ageing on the relationship between ultimate $\mathrm{pH}$ and shear values of beef $\mathrm{m}$. longissimus thoracis. Meat Science, Oxford, v.51, n.2, p.135-41, 1999.

SAS INSTITUTE INC. SAS User's guide: Statistics, Ver 6. $12^{\mathrm{Th}}$. Cary, NC. : SAS, 1996.

SHIMOKOMAKI, M., FRANCO, B.D.G.M., BISCONTINI, T.M. et al. Charqui meats are hurdle technology meat products. Food Reviews International, New York, v.14, n.4, p.339-349, 1998.

UYTTERHAEGEN, L., CLAEYS, E., DEMEYER, D. $\boldsymbol{e} \boldsymbol{t} \boldsymbol{a}$. Effects of double-muscling on carcass quality, beff tenderness and myofibrollar protein degradation in Belgian Blue White bulls. Meat Science, Oxford, v. 38, p.255-267, 1994 